\title{
Population analysis of Endangered northern bottlenose whales on the Scotian Shelf seven years after the establishment of a Marine Protected Area
}

\author{
Kristin O'Brien*, Hal Whitehead \\ Department of Biology, Dalhousie University, Halifax, Nova Scotia B3H 4J1, Canada
}

\begin{abstract}
Marine Protected Areas (MPAs) are being established worldwide to protect vulnerable marine species and habitats, in the face of accelerating rates of species extinctions. Biophysical indicators such as focal species abundance are often employed to assess the effectiveness of MPAs at meeting conservation objectives. We examined the dynamics of an Endangered beaked whale population $7 \mathrm{yr}$ after the Gully MPA was established in 2004 off Nova Scotia, Canada. Northern bottlenose whales forage in deep water such as the Gully submarine canyon. Several MPA restrictions were implemented on the Gully ecosystem beginning in 2004 to reduce anthropogenic impacts including ship traffic, underwater noise and entanglements. This study represents the first intensive northern bottlenose whale population assessment since the Gully became a MPA. Using photo-identification data collected in 2010 and 2011, we applied mark-recapture techniques to estimate the current population size of northern bottlenose whales on the Scotian Shelf as 143 animals (95\% CI: 129 to 156 animals). We also used open population models to examine population trends, and investigated changes in the sex ratio since 1988. Our results suggest the population size and sex ratio have been stable since before MPA legislation was implemented, illustrating the resilience of this population and suggesting that the MPA objective of preventing population decline is being met. Continued monitoring of MPA efficacy is necessary; there is still the potential for future events, whether stochastic or related to climate change, to affect small populations such as the Gully northern bottlenose whales and put the success of MPAs to further test.
\end{abstract}

KEY WORDS: Endangered species - Marine Protected Area $\cdot$ Beaked whale $\cdot$ Population size · Photo-identification · Marine mammal

\section{INTRODUCTION}

Species extinctions are occurring at alarming rates around the world (Pimm et al. 1995), and, as a consequence, there is a growing need to monitor and protect endangered wildlife (Campbell et al. 2002). In many countries, the protection of vulnerable marine species and habitats is increasingly being tackled through the implementation of Marine Protected Areas (MPAs) (Wood et al. 2008). However, the efficacy of MPAs as a conservation tool has been debated (Jameson et al. 2002, Kareiva 2006). Nonetheless, there does seem to be consensus that ongoing evaluations are important for the success and improvement of MPAs (Pomeroy et al. 2005, Thompson et al. 2008, Ojeda-Martínez et al. 2009), and biophysical indicators such as focal species abundance can be measured to determine whether MPA objectives are being met (Pomeroy et al. 2005).

Using this approach, we examined the abundance and population trends of an Endangered beaked whale population in the Gully, a recently established 
MPA located on the Scotian Shelf, offshore Nova Scotia. The availability of long-term data collected decades before and after the establishment of the Gully MPA makes this population an appropriate point of focus to examine changes in abundance coinciding with MPA implementation.

The northern bottlenose whale Hyperoodon ampullatus is a species of beaked whale (family Ziphiidae) that inhabits the North Atlantic Ocean. Northern bottlenose whales forage in deep waters such as submarine canyons where they can dive to $1450 \mathrm{~m}$ (Hooker \& Baird 1999) to feed on deep-water squid (Reeves et al. 1993). One canyon where northern bottlenose whales are regularly sighted is the Gully submarine canyon located on the edge of the Scotian Shelf (Reeves et al. 1993) about $50 \mathrm{~km}$ from Sable Island. It is the largest underwater canyon in the NW Atlantic. Deep waters of the Gully have been identified as critical habitat for this resident population of northern bottlenose whales, and provide a productive habitat for a diversity of marine organisms including other cetaceans (DFO 2008).

Northern bottlenose whales are also found outside of the Gully, in nearby canyons on the Scotian Shelf such as Shortland Canyon (see Fig. 5). Thus, the Gully contains an open population, where whales immigrate and emigrate between the MPA and elsewhere on the Scotian Shelf (Wimmer \& Whitehead 2004). At any one time, the majority of all northern bottlenose whales on the Scotian Shelf (referred to as the Scotian Shelf population) are found in the Gully. Population dynamics of northern bottlenose whales within the Gully have been studied since 1988, and a population estimate made prior to the creation of the MPA suggested that approximately 163 northern bottlenose whales used this and other habitats on the Scotian Shelf (Whitehead \& Wimmer 2005).

Small populations often have lower resilience to natural catastrophes and demographic, environmental and genetic stochasticity (Shaffer 1981). Together, these destabilizing factors can act on small populations to result in reduced evolutionary potential (Frankham 1996) and increased likelihood of extinction (Shaffer 1981). Because long-lived, slow-reproducing animals with stable social and breeding systems are especially vulnerable to extinction (Lacy 2000), conservation has been a major impetus toward furthering our understanding of the population dynamics of northern bottlenose whales on the Scotian Shelf. Eighty-seven northern bottlenose whales from the Gully were taken by commercial whalers operating out of Blandford, Nova Scotia, during the 1960s (Reeves et al. 1993). Whaling off Nova Scotia ended several decades ago; unfortunately, without a baseline population estimate prior to the emergence of commercial whaling, it is difficult to assess the impacts of whaling on this species.

There is significant genetic differentiation between the northern bottlenose whales on the Scotian Shelf and the closest neighbouring population located in the waters off Newfoundland and Labrador (Dalebout et al. 2006). There have not been any photoidentification matches between the Scotian Shelf and the Newfoundland/Labrador populations (although relatively few individuals are known off Newfoundland and Labrador; COSEWIC 2011), and analyses based on mitochondrial DNA suggest that $<5$ females per generation move between these populations (Dalebout et al. 2006).

The genetic distinctiveness of Gully northern bottlenose whales from neighbouring populations (Dalebout et al. 2006), the small population size (Whitehead et al. 1997b) and the suspected vulnerability to environmental degradation (Reeves et al. 1993) prompted the assessment of Scotian Shelf northern bottlenose whales as Endangered by the Committee on the Status of Endangered Wildlife in Canada (COSEWIC) in 2002, and the Species at Risk Act (SARA) in 2006. In 2004, critical habitat of the northern bottlenose whale within the Gully was designated a Marine Protected Area (MPA) (DFO 2008).

In addition to direct hunting, northern bottlenose whales are also thought to be sensitive to current human activities, especially entanglement in fishing gear and noise pollution from shipping and seismic testing such as that related to oil and gas exploration (Hooker et al. 1999, Gowans et al. 2000b, Whitehead \& Hooker 2012). Tourism is also an emerging industry in the Gully MPA, and the future implications of offshore whale-watching activities on whales and their habitat are uncertain.

Human disturbance in the Gully has likely decreased markedly in recent years (Whitehead 2013). At present, commercial ship traffic in the Gully is low (estimated at only 1 ship $\mathrm{d}^{-1}$ ), and with the cessation of both groundfish bottom trawling in areas around the Gully in 1993 and supersonic Concorde air traffic over the Gully in 2003, the Gully habitat has likely become much quieter. Furthermore, pelagic longlining in the core area of the Gully ended with the establishment of the MPA in 2004 (Whitehead 2013). The Gully MPA regulations that were put in place in 2004 also prevent seismic exploration activities within the MPA; however, the sounds of seismic surveys outside the MPA can be heard inside it (McQuinn \& Carrier 2005). 
In addition to less underwater noise, fishing activities within the core area of the MPA, which has been identified as northern bottlenose whale critical habitat, are no longer permitted. The core area of the Gully includes deep waters $>600 \mathrm{~m}$ (DFO 2008); the bathymetry of the Gully submarine canyon is illustrated in Fig. 5. There are, however, restricted fishing activities and types of gear are permitted in peripheral areas of the MPA (DFO 2008), and we have noted sets of drifting fishing gear within the MPA boundaries on at least 2 occasions (authors' unpubl. data). In addition, since whales can leave the MPA, there is still the potential for negative interactions with fisheries activities.

Understanding whether this bottlenose whale population is stable, growing, or in decline is a current conservation priority (DFO 2009). Before the MPA was established no significant trends were identified, suggesting the population was stable (Whitehead \& Wimmer 2005). This study evaluates population trends in the context of recent management changes. Because bottlenose whales are long-lived, slowreproducing animals (Benjaminsen 1972), growth is very difficult to detect over the relatively short time span since the Gully MPA has been established. Thus, our examination of population trends is likely a more appropriate tool to detect population decline, which could potentially occur more rapidly than population growth.

In addition to changes in abundance, whaling could have altered the sex ratio if whalers specifically targeted mature males as was done with sperm whales hunted off Peru (Whitehead et al. 1997a). Whaling on the Scotian Shelf took place between 1962 and 1967, during which records show 87 northern bottlenose whales were killed, although more were likely injured or lost (Reeves et al. 1993). Mature males could have been targeted because they are larger than females and so would produce more oil, and because females do not have spermaceti (Reeves et al. 1993). Altering the age and sex ratios by hunting has been shown to have strong effects on the population growth rates of many ungulates and terrestrial carnivore populations (Milner et al. 2007). By comparing the past and current sex ratios, we examined whether the population demographics of northern bottlenose whales in the Gully have changed over the last $23 \mathrm{yr}$, in order to understand the implications of altered demography on this population's recovery.

The goals of our study were: (1) to determine the population size of northern bottlenose whales in the Gully, (2) to examine population trends to under- stand how the population may have changed since the establishment of the MPA and (3) to examine how the sex ratio has changed over time. Because early studies did not include effort in canyons other than the Gully, all long-term analyses are restricted to only those whales observed in the Gully (referred to as the Gully northern bottlenose whale population). As the unit of management is the Scotian Shelf population, we also produce a current population estimate for the entire Scotian Shelf. Together, our descriptions of population abundance, trends and demographics for northern bottlenose whales in the Gully since the establishment of the MPA will indicate whether present mitigation measures have been sufficient to protect this Endangered beaked whale population from decline.

\section{MATERIALS AND METHODS}

\section{Photograph collection}

Four surveys, each 3 wk in duration, were conducted from the $12 \mathrm{~m}$ auxiliary sailing vessel 'Balaena' during the summer months of 2010 and 2011. Survey effort rotated between the Gully and its neighbouring canyons (Shortland and Haldimand Canyons), with the greatest effort concentrated in the Gully. When northern bottlenose whales Hyperoodon ampullatus were encountered, photographs of both the left and right sides of dorsal fins and melons (foreheads) were taken, and individuals were photographed at random, irrespective of whether or not they had previously been photographed or how well marked they were. Digital photographs were taken with Canon 50D and Canon 20D SLR cameras, each fitted with a fixed $300 \mathrm{~mm}$ lens. Similar field methods for collecting photo-identification data on northern bottlenose whales using film photography have been used since 1988, and are described in detail by Gowans et al. (2000b) and Whitehead \& Wimmer (2005).

\section{Photograph analysis}

Photographs were ranked by quality $(Q)$ based on criteria established by Gowans \& Whitehead (2001). These criteria were originally designed to quality-rate film photographs, so we modified them slightly to allow for the different media type (Fig. 1). Criteria for focus, orientation and proportion of the body visible were quality-rated irrespective of individual mark- 
ings. Exposure was of less consequence, as images could be adjusted in this respect digitally. Additionally, the proportion of the frame occupied by the dorsal fin was not included as a criterion for digital images, because they were of much higher resolution than film photographs. Digital images were instead magnified until the dorsal fin occupied at least onefourth of the frame, after which the sharpness of focus was used to determine the quality of the photograph.

To ensure that even subtly marked individuals could be identified, we restricted the dataset to highquality photographs (Gowans \& Whitehead 2001). If a photograph was ranked poor in one or more criteria it was given a $Q \leq 3$ ranking. $Q=4$ : photographs were good in all criteria; $Q=5$ : were of excellent quality for all criteria, however only the dorsal fin was visible; and $Q=6$ : had excellent quality for all criteria, with the dorsal fin plus the flank ( \pm 1 dorsal fin width) visible. To avoid biasing toward highly identifiable individuals, only photographs rated $Q \geq 4$ were included in all analyses.

The highest quality photograph of each individual identified in each year (2010 and 2011) was used to match between 2010 and 2011 sampling periods (Fig. 2), and then matched by eye to a printed film

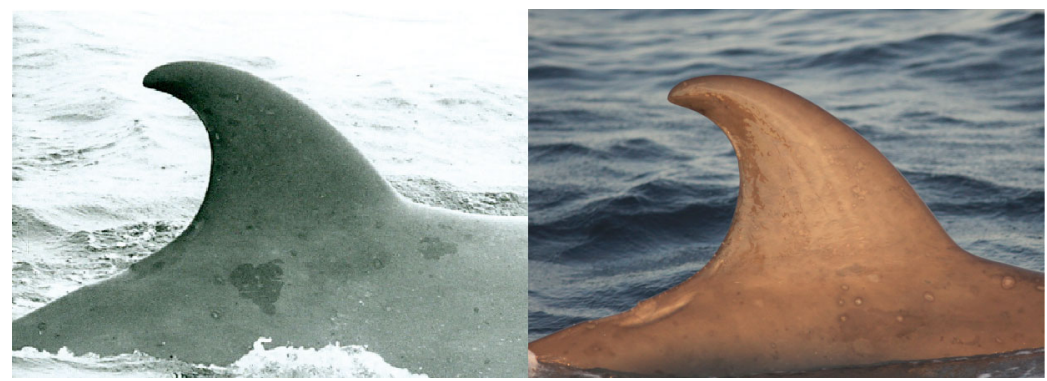

Fig. 1. Hyperoodon ampullatus. Comparison of the best film and best digital photograph of the same individual northern bottlenose whale. Digital photographs are high-resolution colour images, and thus contain additional information that can aid in matching

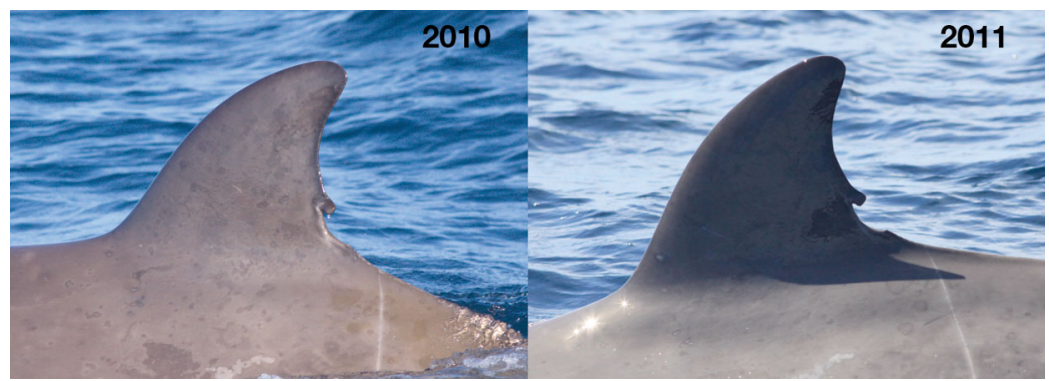

Fig. 2. Hyperoodon ampullatus. The same individual northern bottlenose whale resighted after 1 yr. Individual whales are distinguished by unique marks such as scars on the flank and notches on the dorsal fin catalogue (1988 to 2009), assisted using an 8x magnifying glass. All matches were confirmed by $\mathrm{K}$. O'Brien.

\section{Statistical analyses}

Population size

Two-sample Petersen mark-recapture estimates using Seber modifications (Seber 1982) were conducted for the Scotian Shelf northern bottlenose whale population (the Gully, Shortland and Haldimand), as well as for just the Gully population, on the digital photo-identification data from 2010 and 2011. The following calculation was used where $N_{\mathrm{g}}$ is population size, $n_{1}$ is the number of individuals identified in 2010, $n_{2}$ is the number of individuals identified in 2011 and $m$ is the number of individuals identified in both 2010 and 2011:

$$
N_{\mathrm{g}}=\left(\frac{\left(n_{1}+1\right)\left(n_{2}+1\right)}{(m+1)}\right)-1
$$

All mark types were used to identify individuals over the 12 mo period, with the exception of diatom patches seen on the skin, because the shape of these patches changed rapidly. Left and right dorsal fin side data were analysed separately, and the mean estimates, standard error and confidence intervals were averaged over the 2 sides.

\section{Population trends}

Open-population models were fit to the photo-identification data in order to examine population trends since 1988. Open-population models differ from simpler closed population estimates such as the Petersen markrecapture estimates described above, because open models include additional parameters such as mortality, reimmigration, heterogeneity in identification and/or mortality and a linear population trend. Some of these models are described by Whitehead \& Wimmer (2005); other more complex models such as those with quadratic or piecewise trends and their equations are listed in Table 1. 
Table 1. Hyperoodon ampullatus. We evaluated the fit of 35 candidate open-population models for northern bottlenose whales in the Gully. Models with low support $(5 \leq \Delta \mathrm{AIC} \leq 42)$ were left out for simplicity. Greatest support is indicated by lowest $\Delta$ AIC (Akaike's information criterion) values. The best-supported models are in bold, and all candidate models have associated scaled population estimates $\left(N_{\mathrm{t}}\right)$, AIC values and trends estimated by parameterization ( 2 trends are given for piecewise models). Models were analysed using identifications made from right- and left- sides of dorsal fins separately. Heterogeneity (Het) and identifiability (ID) are abbreviated, and examples of general equations for models with trends are given in the footnotes, where $q$ is a trend (increase or decrease per year), $t$ is the value of the parameter year when it is not specified and $y$ is the value of the parameter year when it is specified in the model

\begin{tabular}{|c|c|c|c|c|c|c|c|c|}
\hline \multirow[t]{2}{*}{ Model } & \multicolumn{4}{|c|}{ Left-side photographs -} & \multirow{2}{*}{$\overline{N_{\mathrm{t}}}$} & \multicolumn{3}{|c|}{ Right-side photographs } \\
\hline & $N_{\mathrm{t}}$ & AIC & $\triangle \mathrm{AIC}$ & $\begin{array}{l}\text { Trend(s) } \\
\left(\% \mathrm{yr}^{-1}\right)\end{array}$ & & AIC & $\Delta \mathrm{AIC}$ & $\begin{array}{l}\text { Trend(s) } \\
\left(\% \mathrm{yr}^{-1}\right)\end{array}$ \\
\hline Het in identifiability & 157 & 1080.37 & 0.25 & & 157 & 1125.91 & $\mathbf{0}$ & \\
\hline Het in ID + linear trend & 157 & 1082.37 & 2.25 & 0 & 157 & 1127.91 & 1.99 & 0 \\
\hline Het in ID and Het in mortality & 157 & 1080.12 & $\mathbf{0}$ & & 158 & 1127.27 & 1.35 & \\
\hline Het in ID and Het in mortality + linear trend & 157 & 1082.12 & 2 & 0 & 157 & 1129.24 & 3.33 & 0 \\
\hline Het in ID + quadratic trend ${ }^{a}$ & 166 & 1083.78 & 3.66 & & 167 & 1129.13 & 3.22 & \\
\hline $\begin{array}{l}\text { Het in ID + stable until year } y \text { then increasing } \\
\text { with trend } q^{\text {b }}\end{array}$ & 157 & 1084.32 & 4.2 & 0 & 159 & 1129.67 & 3.76 & -0.01 \\
\hline $\begin{array}{l}\text { Het in ID + stable until } 2004 \text { then increasing } \\
\text { with trend } q^{\text {b }}\end{array}$ & 157 & 1082.29 & 2.17 & -0.01 & 158 & 1127.79 & 1.88 & -0.01 \\
\hline $\begin{array}{l}\text { Het in ID + stable until } 2003 \text { then increasing } \\
\text { with trend } q^{\mathrm{b}}\end{array}$ & 157 & 1082.32 & 2.2 & -0.01 & 158 & 1127.81 & 1.89 & -0.01 \\
\hline $\begin{array}{l}\text { Het in ID + stable until } 1999 \text { then increasing } \\
\text { with trend } q^{\text {b }}\end{array}$ & 157 & 1082.31 & 2.19 & 0 & 158 & 1127.77 & 1.85 & -0.01 \\
\hline $\begin{array}{l}\text { Het in ID + decreasing with trend } q \text { until } \\
\text { year } y \text { then stable }{ }^{c}\end{array}$ & 160 & 1084.32 & 4.19 & 0 & 164 & 1128.94 & 3.02 & -0.03 \\
\hline $\begin{array}{l}\text { Het in ID + decreasing with trend } q \text { until } \\
2004 \text { then stable }{ }^{\mathrm{c}}\end{array}$ & 160 & 1082.35 & 2.23 & 0 & 158 & 1127.91 & 1.99 & 0 \\
\hline $\begin{array}{l}\text { Het in ID + decreasing with trend } q \text { until } \\
2003 \text { then stable }{ }^{\mathrm{c}}\end{array}$ & 159 & 1082.36 & 2.23 & 0 & 159 & 1127.9 & 1.99 & 0 \\
\hline $\begin{array}{l}\text { Het in ID + decreasing with trend } q \text { until } \\
1999 \text { then stable }\end{array}$ & 161 & 1082.29 & 2.17 & -0.01 & 162 & 1127.77 & 1.86 & -0.01 \\
\hline Het in ID + piecewise trend ${ }^{\mathrm{d}}(y=2004)$ & 169 & 1084.14 & 4.01 & $\begin{array}{l}-0.02 \\
-0.01\end{array}$ & 170 & 1129.61 & 3.7 & $\begin{array}{l}-0.02 \\
-0.01\end{array}$ \\
\hline Het in ID + piecewise trend $d^{d}(y=2003)$ & 165 & 1084.24 & 4.11 & $\begin{array}{l}-0.01 \\
-0.01\end{array}$ & 168 & 1129.66 & 3.74 & $\begin{array}{l}-0.01 \\
-0.01\end{array}$ \\
\hline Het in ID + piecewise trend ${ }^{\mathrm{d}}(y=1999)$ & 164 & 1084.16 & 4.04 & $\begin{array}{l}-0.01 \\
-0.01\end{array}$ & 168 & 1129.41 & 3.5 & $\begin{array}{l}-0.01 \\
-0.01\end{array}$ \\
\hline
\end{tabular}

Piecewise trends were included to examine scenarios where population trends differed before and after a given year. This transition year was specified in the model as a year when major environmental changes occurred such as 1999 (when the highest seismic noise was recorded on the Scotian Shelf; COSEWIC 2011), 2003 (when several oil spills occurred near Sable Island; Hooker et al. 2008) and 2004 (when the Gully became a MPA). If the year was not specified it was estimated by parameterization. Thirty-five candidate models were fit to the northern bottlenose whale photo-identification data, and model preference was determined by Akaike's information criterion (AIC), which evaluates how well a model is supported by the data, while compensating for the inclusion of addi- tional parameters (Burnham \& Anderson 2002). Parameter values and $95 \%$ confidence intervals (CI) were estimated using maximum likelihood.

To prevent bias in effort between locations (the Gully was surveyed since 1988 whereas visits to Shortland and Haldimand began in 2003), we only included data that were collected in the Gully in the trend analysis. Due to the long time span of the analysis (23 yr), we met the assumption that animals do not lose their marks between sampling periods by restricting long-term analyses to reliably marked individuals, those with notches in the dorsal fin, back indents, and/or mottled patches which have been shown to persist over many years (Gowans \& Whitehead 2001). 
Open-population modeling analyses were conducted only on reliably marked individuals, and estimates of population size for marked individuals $\left(N_{\mathrm{m}}\right)$ were then scaled to account for the proportion of the population without reliable marks, by multiplying $N_{\mathrm{m}}$ by $h$, the proportion of reliably marked individuals within the entire population (Whitehead \& Wimmer 2005).

We estimated $h$ as the ratio of all high-quality photographs $(Q \geq 4)$ to those photographs of reliably marked whales (left- and right-side photographs combined). After calculating this ratio separately for each year, we estimated the coefficient of variation $\mathrm{CV}(h)$ by dividing the standard deviation weighted by the number of high-quality photographs by the sample mean. The mean population estimate for the total population of whales (reliably and unreliably marked) in the Gully $\left(N_{\mathrm{t}}\right)$ and upper and lower 95\% CI from the best-supported model for each fin side were determined using the following equation adapted from Whitehead \& Wimmer (2005):

$$
\mathrm{CI}\left(N_{1}\right)=N_{1} \pm 1.96 N_{1} \sqrt{\mathrm{CV}(h)^{2}+\left\{\frac{\left[\mathrm{CI}\left(N_{\mathrm{m}}\right)-N_{\mathrm{m}}\right]}{1.96 N_{\mathrm{m}}}\right\}^{2}}
$$

Estimates for $N_{\mathrm{t}}$ and CI $\left(N_{\mathrm{t}}\right)$ from right- and left-side dorsal fin photographs were then averaged. All population modeling was done using the statistical software SOCPROG (Whitehead 2009).

\section{Changes in the sex-ratio over time}

We examined the melon photographs of all individuals identified from high-quality dorsal fin photographs in 2010 and 2011. Melon photographs were quality rated and assigned to 1 of 3 age/sex classes based on secondary sexual characteristics (Fig. 3), following the methods described by Gowans et al. (2000a). The first class included immature whales (male and female) and adult females (F) because they have melon characteristics that are indistinguishable from each other. The second class was comprised of subadult males (SM) who had begun to develop secondary sexual characteristics including flattening of the anterior melon. The third class consisted of mature males (MM) whose melons were square in profile and white in color.

For each year (1988 to 2011), we expressed the number of whales in each sex class as a ratio of the total number of whales for which the sex was determined. We then tested how well the term 'year' predicted the above ratio for each sex class using a generalized linear model with a binomial distribution, performed in $\mathrm{R}$ (R Core Team 2012). The AIC values for null and complete models were compared by stepwise regression to determine if 'year' was a useful predictor of the sex ratio. Also, the p-value of the goodness-of-fit for the variable 'year' was estimated in order to test whether a significant trend was observed for any of the age/sex classes from 1988 to 2011.

\section{RESULTS}

\section{Population size}

For the Scotian Shelf population of Hyperoodon ampullatus, a total of 4147 high-quality photographs from 2010 and 2011 were of sufficient quality to include in the analyses, from which 127 (right) and 121 (left) unique individuals were identified. Peterson mark-recapture estimates from 2010 and 2011 data were 150 animals (95\% CI = 135 to 165 animals) from the analysis of right dorsal fin side photographs, and 136 animals (95\% CI = 125 to 147 animals) using left-side photographs. The average estimate of northern bottlenose whales on the Scotian Shelf was 143 animals ( $\mathrm{SE}=7.9,95 \% \mathrm{CI}=129$ to 156 animals). In total, we photographed $89 \%$ (95\% CI $=81$ to $98 \%$ ) of the estimated total population.

For the population that uses the Gully, a total of 3272 high-quality photographs from 2010 and 2011 were included, from which 94 (right) and 92 (left) unique individuals were identified. Peterson
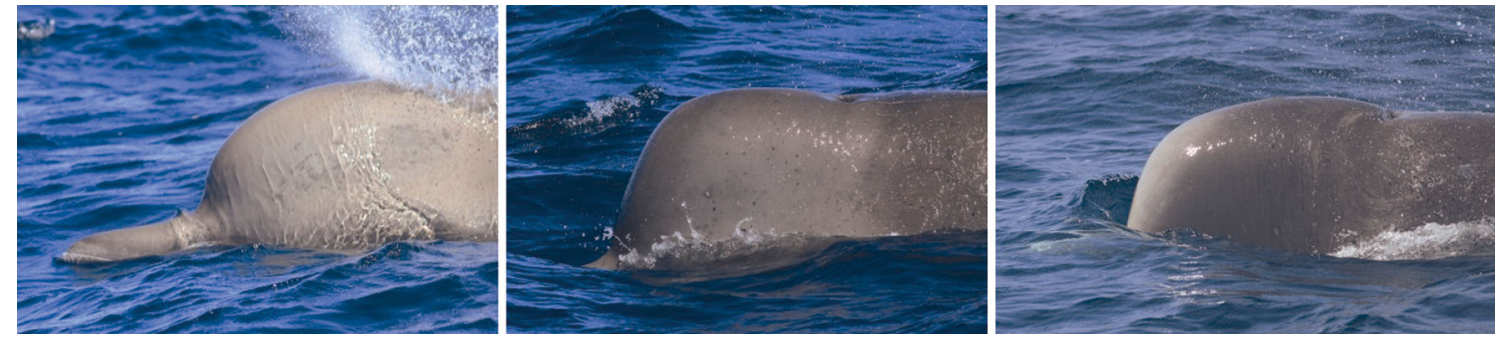

Fig. 3. Hyperoodon ampullatus. Examples of variation in melon shape and colouration for the female/immature ( $F_{i}$ left panel), subadult male (SM; middle panel) and mature male (MM; right panel) age/sex classes of northern bottlenose whales 
mark-recapture estimates from 2010 and 2011 data were 121 animals ( $95 \% \mathrm{CI}=105$ to 137 animals) and 110 animals $(95 \% \mathrm{CI}=98$ to 122 animals) from photographs of right and left dorsal fin sides, respectively. The average estimate of northern bottlenose whales in the Gully was 116 animals (SE $=8.7,95 \%$ $\mathrm{CI}=101$ to 130 animals $)$, of which $81 \%(95 \% \mathrm{CI}=72$ to $93 \%$ ) of the animals were photographed.

\section{Population trends}

In total, 3153 left and 2960 right dorsal fin side photographs collected between 1988 and 2011 were of sufficient quality to be included in the analyses (of which 1227 left and 1219 right dorsal fin side photographs were collected between 2010 and 2011). A list of candidate models with moderate to high support is provided in Table 1, along with their associated AIC and $\triangle$ AIC values, scaled population estimates and estimated trend parameters. The models with the lowest AIC values, and that therefore were best supported by the photo-identification data, included the parameters mortality and heterogeneity in identifiability (right-side photographs) and heterogeneity in mortality and identifiability (left-side photographs) (parameters in bold; Table 1). Parameter estimates from the best-supported open-population models are listed in Table 2.

Similar to closed-population models, open-population models also generate estimates of population size. The most recent population estimates (2011) of reliably marked individuals within the population were the same for both dorsal fin sides, at 107 animals ( $95 \%$ CI $=92$ to 128 animals). The proportion of high-quality photographs to those showing individuals with reliable marks was $1.46(\mathrm{CV}=0.12)$, yielding scaled estimates of total population size for the Gully northern bottlenose whale population of 158 animals (95\% CI $=114$ to 205 animals) from right-side photographs and 157 animals $(95 \% \mathrm{CI}=113$ to 205 animals) from left-side photographs. After averaging

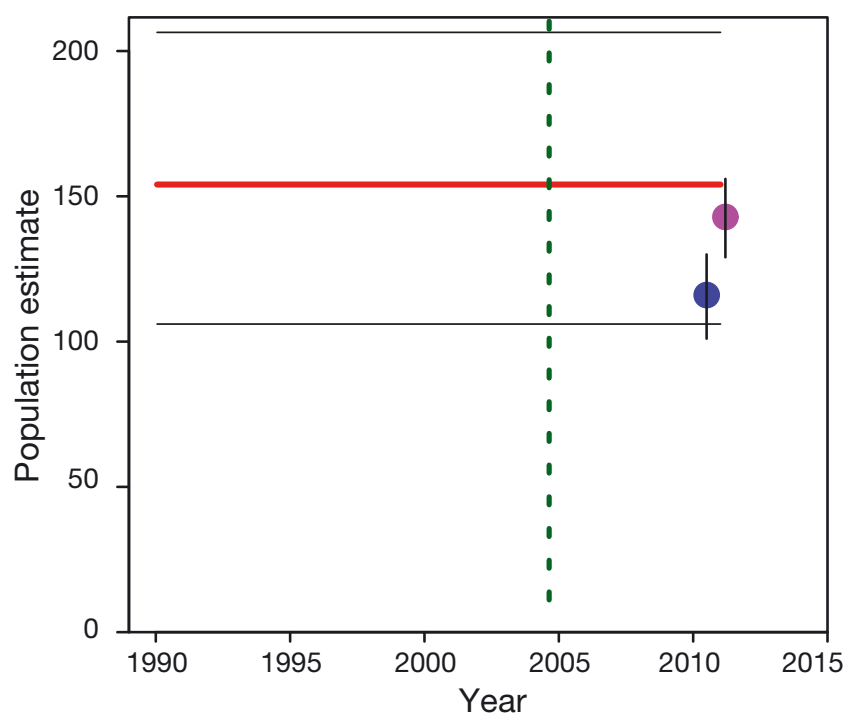

Fig. 4. Hyperoodon ampullatus. Comparison of population estimates derived from different methods. The red line shows a stable population of $H$. ampullatus using the Gully since 1988 and was derived using open population models. Closed population models based on data from 2010 and 2011 only yielded similar population estimates for data collected in the Gully only (blue circle), and a also a slightly larger estimate for the number of animals that use habitat across the Scotian Shelf (magenta circle). The blue circle has been gittered for clarity. Estimates in this figure are averages of population estimates calculated separately for left and right dorsal fin data. Error bars (horizontal and vertical black lines) represent the $95 \%$ CI around estimates, and the dashed green line shows when the Gully Marine Protected Area was established in 2004

both dorsal fin sides, the estimate for the entire Gully population was 157 animals (95\% CI $=113$ to 205) animals. Because population estimates for open and closed models differed, they were plotted sideby-side on Fig. 4 for comparison.

Regardless of the dorsal fin side, the same 2 models described in Table 2 were best supported by the photo-identification data. The second best models for each side had moderate support, indicated by only a small difference in AIC values compared to the bestsupported models ( $\triangle \mathrm{AIC}$ of 0.24 for left sides and 1.35

Table 2. Hyperoodon ampullatus. Parameter estimates for the best-supported models from left- and right-side dorsal fin photoidentifications of northern bottlenose whales in the Gully, as well as side-averaged parameter estimates. Parameter estimates are presented as mean (likelihood $95 \%$ CI). NA: not applicable

\begin{tabular}{|c|c|c|c|}
\hline \multirow{2}{*}{ Parameter } & \multirow[b]{2}{*}{ Right dorsal fins } & \multirow{2}{*}{$\begin{array}{l}\text { Parameter estimate } \\
\text { Left dorsal fins }\end{array}$} & \\
\hline & & & Average \\
\hline Mortality rate & $0.09(0.07-0.11)$ & $0.13(0.08-0.18)$ & $0.11(0.07-0.15)$ \\
\hline $\begin{array}{l}\text { Proportion of low-mortality/low- } \\
\text { identifiability individuals }\end{array}$ & $0.68(0.52-0.85)$ & $0.71(0.51-0.86)$ & $0.70(0.51-0.85)$ \\
\hline Mortality rate of low-mortality individuals & NA & $0.07(0.03-0.11)$ & NA \\
\hline
\end{tabular}


for right sides). There was much less support for all models that included linear, quadratic, or piecewise trends, as indicated by higher AIC values. Adding a linear population trend to the parameters of the simplest and best supported candidate model, the esti- mated population trends using left- and right-side photo-identifications, respectively, were $-0.08 \% \mathrm{yr}^{-1}$ and $-0.01 \% \mathrm{yr}^{-1}$, and averaging these trends (as well as their respective $95 \% \mathrm{CI}$ ) yielded a side-averaged trend of $-0.05 \mathrm{yr}^{-1}\left(95 \% \mathrm{CI}=-2.0\right.$ to $\left.2.0 \% \mathrm{yr}^{-1}\right)$.

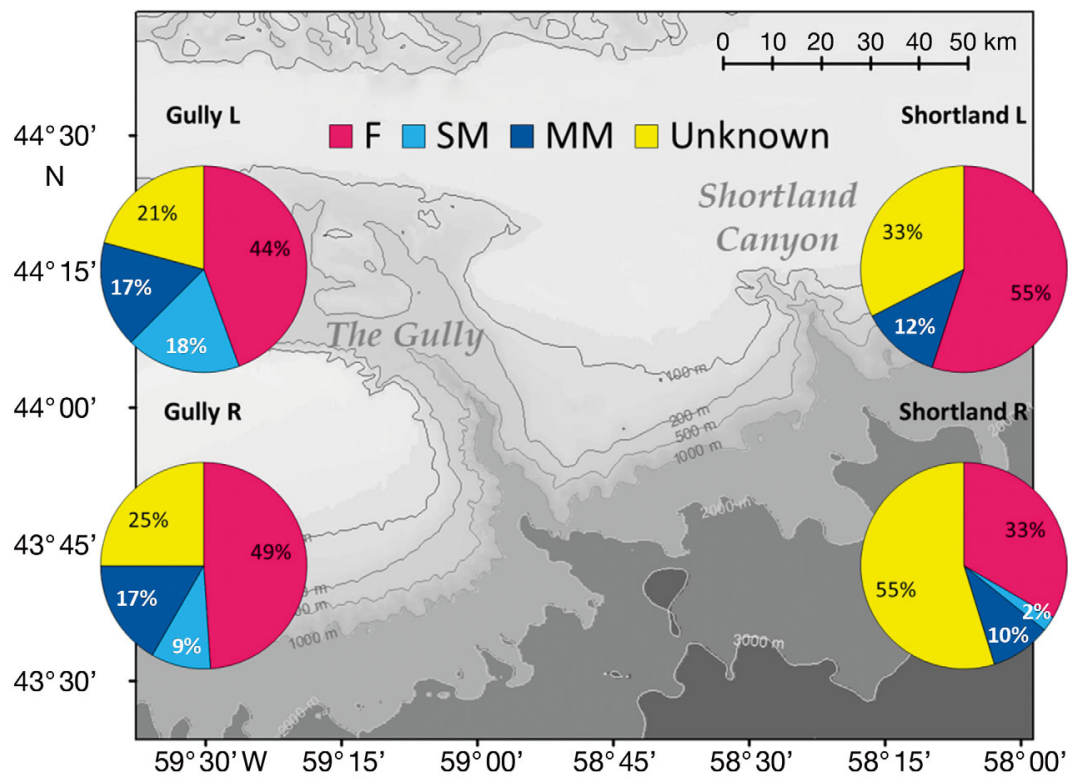

Fig. 5. Hyperoodon ampullatus. Current (based on 2010 to 2011 data) age and sex structure of whales found in the Gully and Shortland Canyon. Separate analyses were conducted using photo-identification data from left (L) and right $(\mathrm{R})$ dorsal fin sides, and results for both sides are presented for comparison. Age/sex classes are abbreviated as females/immature animals (F), subadult males (SM) and mature males (MM)

Table 3. Hyperoodon ampullatus. Fit of models for each age/sex class predicted by year, compared to the fit of the corresponding null models. Support for models with year as a predictor are indicated by a lower $\triangle$ AIC (Akaike's information criterion) compared to the null model; $\mathrm{p}$-values are estimates of the probability that a parameter was included in a model by chance, and thus indicates the utility of including that parameter in the model. F: females; SM: subadult males; MM: mature males

\begin{tabular}{|clccccccc|}
\hline \multirow{2}{*}{$\begin{array}{c}\text { Fin } \\
\text { side }\end{array}$} & \multirow{2}{*}{$\begin{array}{l}\text { Model } \\
\text { predictors }\end{array}$} & \multirow{2}{*}{ AIC } & \multirow{2}{*}{$\Delta$ AIC } & \multicolumn{5}{c|}{ Coefficients } \\
\cline { 6 - 8 } Left & & & & Term & Estimate & SE & $\mathrm{p}$ \\
& Full & 68.391 & 0 & (Intercept) & 36.266 & 24.475 & 0.138 \\
& Null & 68.514 & 0.123 & Year & 0.018 & 0.012 & 0.145 \\
& MM Year & 69.250 & 0.022 & (Intercept) & 42.117 & 31.031 & 0.175 \\
& Null & 69.228 & 0 & Year & -0.022 & 0.016 & 0.163 \\
& SM Year & 61.757 & 0.625 & (Intercept) & 48.036 & 43.412 & 0.269 \\
& Null & 61.127 & 0 & Year & -0.025 & 0.022 & 0.249 \\
Right & F Year & 72.151 & 0.914 & (Intercept) & 25.535 & 23.907 & 0.285 \\
& Null & 71.237 & 0 & Year & 0.012 & 0.012 & 0.297 \\
& MM Year & 69.086 & 1.857 & (Intercept) & 9.856 & 28.995 & 0.734 \\
& Null & 67.229 & 0 & Year & -0.005 & 0.015 & 0.706 \\
& SM Year & 59.774 & 0 & (Intercept) & 82.966 & 45.592 & 0.069 \\
& Null & 61.469 & 1.695 & Year & -0.0423 & 0.023 & 0.062 \\
\hline
\end{tabular}

\section{Changes in the sex ratio over time}

The most abundant age/sex class was females/immature animals (Fig. 5). We analysed photographs of the left and right sides of melons separately, and there was agreement between the 2 sides. The sex ratios were also quite similar between the Gully and Shortland Canyon, except for subadult males who were more common in the Gully (Fig. 5).

The term 'year' did not appear to be a useful predictor of the number of individuals of any sex class across time ( $p>0.05$; Table 3). Also, models that included the variable 'year' as a predictor generally had less support than their corresponding null models, as indicated by lower AIC values (Table 3). This suggests the sex ratio has not changed significantly between 1988 and 2011.

\section{DISCUSSION}

Using closed-population models, we estimated that the current population size of northern bottlenose whales Hyperoodon ampullatus in the Gully is 116 animals ( $\mathrm{SE}=8.7,95 \% \mathrm{CI}=101$ to 130 animals). Our population size estimate based on open-population models (157 animals, 95\% CI = 113 to 205) was similar, although less precise (Fig. 4). Our estimates are consistent with past studies of this population that used open-population models (Whitehead et al. 1997b, Gowans et al. 2000b, Whitehead \& Wimmer 2005). While open-population models are useful for exploring temporal trends, population size is often estimated with greater uncertainty. The closedpopulation estimates presented in this 
study are more precise then the open-population estimates largely as a result of high survey effort in 2010 and 2011 combined with higher quality and greater numbers of digital photographs, which increased the likelihood of capturing excellent images of each individual. High-quality digital photographs allowed fine details of nicks and marks to be resolved, and so for our closed-population estimates of the Gully and Scotian Shelf populations, all of the individuals in high-quality photographs could be identified. Thus, in contrast to the open models, there was no need to scale the closed-population estimates to account for non-marked individuals. As a result, uncertainty around closed-population estimates was not confounded by error introduced by scaling. Finally, a very high proportion of the Scotian Shelf population was actually observed $(89 \%$; $95 \%$ CI $=81$ to $98 \%$ ), and Petersen mark-recapture analyses have very little bias at such high sample sizes (Robson \& Regier 1964).

One age class that may have been underestimated in this analysis is young calves, and it is possible that our estimate of population size could be slightly conservative as a result. In general, photographs of calves seemed to have low quality-ratings, often because of poor focus or exposure which made it impossible to see subtle marks and scars on the skin. Since observations of calves are rare in the Gully, underrepresentation of calves in the photo-identification analyses probably would not have a noticeable effect on population estimates.

Because northern bottlenose whales in the Gully are part of a larger Scotian Shelf population (which includes the Gully, Shortland and Haldimand Canyons), we estimated the population size of whales on the entire Scotian Shelf, 143 animals (SE = $7.9,95 \% \mathrm{CI}=129$ to 156 animals). This is only slightly larger than the Gully estimate which means that most of northern bottlenose whales on the Scotian Shelf have been observed within the Gully MPA. Since the Scotian Shelf population is not fully mixed (Wimmer \& Whitehead 2004) and whales can enter and leave the Gully MPA, current legislation within the MPA will not protect them at all times. However, Hooker \& Gerber (2004) note that MPAs can be beneficial even if a marine predator does not remain exclusively within the MPA boundaries, by reducing the frequency an animal encounters anthropogenic threats.

To examine population trends in long-term data (since 1988), open-population models were explored as they account for mortality, births, immigration and emigration-dynamics which cannot be ignored over multiple decades. Mark-recapture techniques assume homogenous capture and recapture probabilities among all individuals in a population. However, heterogeneity in the identifiability of individuals resulting from individual variation in behaviour or morphology is thought to be common if not ubiquitous among mark-recapture studies of cetaceans (Hammond 1986, 1990). Heterogeneous capture probabilities among other cetacean populations have been documented, for example, humpback whales in the Gulf of Maine (Hammond 1990) and sperm whales off the Azores (Matthews et al. 2001).

We attempted to account for heterogeneity in identifiability in 3 ways. First, we only used high-quality photographs, so that even subtly marked individuals could be identified. Second, we restricted the analysis to include only individuals with mark types that are retained over many years and, third, we built models that attempted to account for remaining heterogeneity in identifiability. Factors such as agespecific biases in mortality can lead to violation of the assumption that mortality rates are homogenous, especially when mark-recapture analyses are applied over longer temporal scales (Hammond 1986). We included candidate models in this analyses that incorporated heterogeneity in identifiability and/or mortality by dividing the population into 2 groups, and allowing the probability of mortality or identification to differ between groups but not within groups. Similar to past research on this population (Whitehead \& Wimmer 2005), the models that included heterogeneity in identifiability and/or mortality best fit the data.

Before the MPA was established, there was no detectable population trend in the Gully (Whitehead \& Wimmer 2005). The inclusion of data collected since 2004 added a substantially greater time span over which to examine population trends, and considerably increased power to detect non-linear trends. The fact that none of the complex models incorporating a linear or a non-linear trend were selected for, despite the higher power of this analysis, provides further support that the current population size of northern bottlenose whales in the Gully is stable. The best-supported model with a trend had a $95 \%$ CI of -2.0 to $2.0 \% \mathrm{yr}^{-1}$, suggesting that, while stable, the population could be decreasing or increasing within a net range of \pm 3 animals $\mathrm{yr}^{-1}$.

The estimated mortality rate was $11 \%(95 \% \mathrm{CI}=7$ to $15 \%$ ), which seems unrealistic given this cetacean population is stable. Overestimated rates of mortality could have been the result of violating the assumption that 'reliable' marks do not change over time, 
which could occur if a 'reliable' mark became obscured by a new mark. Such changes would not affect our estimate of population size, but would inflate our estimate of mortality. It is also possible, however, that activities outside of the MPA (e.g. fishing, ship traffic, or underwater noise) could influence mortality given that the whales can move in and out of the MPA.

Since survey effort focused only on the Gully in the years from 1988 to 2002, the results of these models, including estimates of population trends and mortality, are limited to the Gully and can not be generalized for the Scotian Shelf population as a whole. However, the Gully is the only part of the Scotian Shelf northern bottlenose whale habitat that has been protected as a MPA and, thus, provides an appropriate scale to examine the effectiveness of current conservation initiatives.

We do not know why the population size of northern bottlenose whales in the Gully is so small. It is possible the small population size is due to depletion from past whaling (Reeves et al. 1993), current anthropogenic factors depressing population growth, or that the population has recovered from past exploitation and has stabilized at or near the carrying capacity of the Gully environment (DFO 2009). Genetics have provided support that the population size was small even before the emergence of commercial whaling in this region (Dalebout et al. 2006). Understanding the mechanisms regulating population size will likely only be resolved with long-term monitoring of this population beyond the scope of this study.

Based on the current age/sex structure of the Scotian Shelf population, the Gully appears to be important habitat for groups of bottlenose whales comprised of mature males, females and subadult males, whereas areas outside of the MPA may be used less by subadult males. Assigning individuals to qualitative age/sex classes based on melon shape is inherently subjective, although classification of all whales in 2010 to 2011 was determined by a single observer. Thus, observer bias cannot explain the fewer sightings of subadult males in Shortland Canyon. There is, however, a greater proportion of whales of unknown age/sex in Shortland Canyon, indicating the pattern we observed warrants further study.

While classifying the sex of whales, we noticed 2 individuals (Nos. 2013 and 293) who were classified as mature males in 2011 based on melon shape (square in profile), and, despite being relatively old, their melons had not yet turned white. Individual No. 2013 was first identified in 2002 and was seen again in 2011, so he was at least 9 yr old (and could have been much older). Individual No. 293 was first identified in 1990, so he was at least 21 yr old when he was resighted in 2011. This seemed to contradict the general description of mature male bottlenose whales as having melons that are white in colour (Reeves et al. 1993). Benjaminsen \& Christensen (1979) estimated that male northern bottlenose whales caught off Labrador matured between 7 and $11 \mathrm{yr}$, and whales older than this were considered sexually mature males. Their measurements were determined by examining the histology of testes from whales hunted in this region. Our examinations of melons suggest that either mature males develop white melon colouration at a later age than was previously thought or that not all mature males acquire this characteristic.

Similar to our findings for population abundance, there was no evidence that the sex ratio has changed significantly over time, despite whaling losses in the past. Humans often selectively hunt animal populations (Milner et al. 2007), for example, by removing large males in sexually dimorphic species (Whitehead et al. 1997a). Two-thirds of the northern bottlenose whales that were taken by whalers off Nova Scotia, and that were sexed, were males (Reeves et al. 1993). Our results suggest that either whaling did not destabilize the sex ratio prior to this study (starting in 1988) or that any deviations in the sex ratio had already equilibrated by 1988 . Since we are only considering changes in measures of sex ratio, we cannot exclude the possibility there could be an undetected sex bias in the immature whales (who have not yet matured enough to develop the morphological differences necessary to visually distinguish their sex).

Our study set out to investigate whether the conservation objectives of the Gully MPA are being met under the present level of habitat protection. The conservation goal for northern bottlenose whales on the Scotian Shelf is to maintain at least a stable population (DFO 2009). Our results suggest that both the population size and demographics have been stable since before the establishment of the MPA, and remain so. However, future events, whether stochastic or related to climate change (Hoegh-Guldberg \& Bruno 2010), may have the potential of affecting this population and putting the effectiveness of this MPA to further test.

While this study did not directly test the effect of a MPA on population viability, it seems probable that decreased levels of anthropogenic disturbance in the habitat (for example, reduced noise and fishing activities) have positively influenced this population of 
northern bottlenose whales and will continue to do so in the future. Life-history characteristics constrain population growth rates of large odontocetes to be small — only a few percent (Wade 1998). Our results show that the population could be increasing (or decreasing) up to a maximum of $2 \% \mathrm{yr}^{-1}$; thus, we are likely examining this situation too early to detect any significant benefits of MPA regulations on population growth. Similarly, the $23 \mathrm{yr}$ time span over which the sex ratio was examined may be too short to detect the small changes which are all that might be expected given this species is long-lived and slow to reproduce. Continued monitoring of northern bottlenose whales in the Gully will not only increase our capacity to detect small but important trends in population abundance, but will also help us better understand the stability of the sex ratio for this population.

In a long-term study of a resident population of Hector's dolphins Cephalorhynchus hectori off New Zealand, Gormley et al. (2012) found empirical evidence of an increase in the population growth rate coinciding with MPA implementation. The population dynamics of Hector's dolphins were monitored over the 24 yr their habitat had been designated a MPA. The work of Gormley et al. (2012) not only illustrates the success of area-based management for an endangered cetacean population, but it also shows the benefit of long-term monitoring to evaluate MPA efficacy.

Small populations are thought to be at greater risk of extinction (Shaffer 1981); thus, continued monitoring of this Endangered population will be critical in future years to help ensure that if population decline occurs, it can be detected early so that mitigation strategies can be adapted. A portion of this population has been sampled using genetic techniques (Gowans et al. 2000a, Dalebout et al. 2001, 2006), and future work using biopsy samples could yield considerable insight toward discerning the sex of individuals as well as their relatedness, movements, diet and reproductive status, and links to other populations. Such information could further our understanding of this small population of northern bottlenose whales and their recovery. The Gully MPA was created for broad-scale ecosystem and biodiversity conservation (Westhead et al. 2012). While our results are limited to understanding the status of 1 cetacean species in this ecosystem, marine predators such as cetaceans may be especially useful focal species to indicate widescale ecosystem change (Hoyt 2011) and thus may provide insight as we strive to conserve productive marine habitats such as the Gully.
Acknowledgements. We thank the past and recent crew members of 'Balaena', laboratory volunteers and all the members of the Whitehead laboratory who built the foundations for long-term research of northern bottlenose whales in the Gully, and who helped make recent field seasons possible. The background map in Fig. 5 was provided by $\mathrm{H}$. Moors-Murphy. This research was funded by the Canadian Wildlife Federation, National Sciences and Engineering Research Council of Canada and Dalhousie University. Earlier work on this project was funded by Wildlife Fund Canada-Environment Canada Endangered Species Recovery Fund, the Canadian Whale Institute, the Island Foundation, the Whale and Dolphin Conservation Society, the National Geographic Society and the Department of Fisheries and Oceans Canada. We also thank M. Leonard, as well as B. L. Chilvers and 2 anonymous reviewers for ESR for providing valuable comments on the manuscript.

\section{LITERATURE CITED}

Benjaminsen $\mathrm{T}$ (1972) On the biology of the bottlenose whale, Hyperoodon ampullatus (Forster). Norw J Zool 20:233-241

Benjaminsen T, Christensen I (1979) The natural history of the bottlenose whale, Hyperoodon ampullatus. In: Winn $\mathrm{H}_{\text {, }}$ Olla L (eds) Behaviour of marine animals: current perspectives in research. Plenum Press, New York, NY, p 143-164

Burnham KP, Anderson DR (2002) Model selection and multimodel inference: a practical information-theoretical approach, 2nd edn. Springer-Verlag, New York, NY

Campbell SP, Clark JA, Crampton LH, Guerry AD and others (2002) An assessment of monitoring efforts in endangered species recovery plans. Ecol Appl 12:674-681

COSEWIC (Committee on the Status of Endangered Wildlife in Canada) (2011) COSEWIC assessment and status report on the northern bottlenose whale Hyperoodon ampullatus in Canada. COSEWIC, Ottawa

Dalebout ML, Hooker SK, Christensen I (2001) Genetic diversity and population structure among northern bottlenose whales, Hyperoodon ampullatus, in the western North Atlantic Ocean. Can J Zool 79:478-484

> Dalebout ML, Ruzzante DE, Whitehead H, Øien NI (2006) Nuclear and mitochondrial markers reveal distinctiveness of a small population of bottlenose whales (Hyperoodon ampullatus) in the western North Atlantic. Mol Ecol 15:3115-3129

DFO (Department of Fisheries and Oceans Canada) (2008) The Gully Marine Protected Area Management Plan. Oceans and Habitat Branch, DFO, Dartmouth, NS

DFO (Department of Fisheries and Oceans Canada) (2009) Recovery strategy for the northern bottlenose whale (Hyperoodon ampullatus), Scotian Shelf population, in Atlantic Canadian Waters [Proposed]. Species at Risk Act Recovery Strategy Series, DFO, Dartmouth, NS

> Frankham R (1996) Relationship of genetic variation to population size in wildlife. Conserv Biol 10:1500-1508

Gormley AM, Slooten E, Dawson S, Barker RJ, Rayment W, du Fresne S, Bräger S (2012) First evidence that marine protected areas can work for marine mammals. J Appl Ecol 49:474-480

Gowans S, Whitehead H (2001) Photographic identification of northern bottlenose whales (Hyperoodon ampullatus): sources of heterogeneity from natural marks. Mar Mamm Sci 17:76-93 
Gowans S, Dalebout ML, Hooker SK, Whitehead H (2000a) Reliability of photographic and molecular techniques for sexing northern bottlenose whales (Hyperoodon ampullatus). Can J Zool 78:1224-1229

Gowans S, Whitehead H, Arch JK, Hooker SK (2000b) Population size and residency patterns of northern bottlenose whales (Hyperoodon ampullatus) using the Gully, Nova Scotia. J Cetacean Res Manag 2:201-210

Hammond PS (1986) Examining the size of naturally marked whale populations using capture-recapture techniques. Rep Int Whal Comm Spec Issue 8:253-282

Hammond PS (1990) Heterogeneity in the Gulf of Maine? Estimating humpback whale population size when capture probabilities are not equal. Rep Int Whal Comm Spec Issue 12:135-139

Hoegh-Guldberg O, Bruno JF (2010) The impact of climate change on the world's marine ecosystems. Science 328: 1523-1528

Hooker SK, Baird RW (1999) Deep-diving behaviour of the northern bottlenose whale, Hyperoodon ampullatus (Cetacea: Ziphiidae). Proc R Soc Lond B Biol Sci 266: 671-676

> Hooker SK, Gerber LR (2004) Marine reserves as a tool for ecosystem-based management: the potential importance of megafauna. Bioscience 54:27-39

> Hooker SK, Whitehead H, Gowans S (1999) Marine protected area design and the spatial and temporal distribution of cetaceans in a submarine canyon. Conserv Biol 13:592-602

Hooker SK, Metcalfe TL, Metcalfe CD, Angell CM, Wilson JY, Moore MJ, Whitehead H (2008) Changes in persistent contaminant concentration and CYP1A1 protein expression in biopsy samples from northern bottlenose whales, Hyperoodon ampullatus, following the onset of nearby oil and gas development. Environ Pollut 152: 205-216

Hoyt E (2011) Marine protected areas for whales, dolphins and porpoises, 2nd edn. Earthscan, New York, NY

Jameson SC, Tupper MH, Ridley JM (2002) The three screen doors: Can marine 'protected' areas be effective? Mar Pollut Bull 44:1177-1183

Kareiva P (2006) Conservation biology: beyond marine protected areas. Curr Biol 16:R533-R535

Lacy RC (2000) Considering threats to the viability of small populations using individual-based models. Ecol Bull 48: 39-51

Matthews JN, Steiner L, Gordon J (2001) Mark-recapture analysis of sperm whale (Physeter macrocephalus) photo-id data from the Azores (1987-1995). J Cetacean Res Manag 3:219-226

McQuinn IH, Carrier D (2005) Far-field measurements of seismic airgun array pulses in the Nova Scotia Gully Marine Protected Area. In: Lee K, Brian H, Hurley GV (eds) Acoustic monitoring and marine mammal surveys in the Gully and outer Scotian Shelf before and during active seismic programs. Environmental Studies Research Funds Report No. 151, Department of Fisheries and Oceans, Dartmouth, NS, p 57-74

Milner JM, Nilsen EB, Andreassen HP (2007) Demographic side effects of selective hunting in ungulates and carnivores. Conserv Biol 21:36-47

Editorial responsibility: Louise Chilvers, Wellington, New Zealand
Ojeda-Martínez C, Casalduero FG, Bayle-Sempere JT, Cebrián CB and others (2009) A conceptual framework for the integral management of marine protected areas. Ocean Coast Manag 52:89-101

Pimm SL, Russell GJ, Gittleman J, Brooks TM (1995) The future of biodiversity. Science 269:347-350

> Pomeroy RS, Watson LM, Parks JE, Cid GA (2005) How is your MPA doing? A methodology for evaluating the management effectiveness of marine protected areas. Ocean Coast Manag 48:485-502

R Core Team (2012) R: a language and environment for statistical computing. R Foundation for Statistical Computing, Vienna

Reeves RR, Mitchell E, Whitehead H (1993) Status of the northern bottlenose whale, Hyperoodon ampullatus. Can Field Nat 107:490-508

> Robson DS, Regier HA (1964) Sample size in Petersen markrecapture experiments. Trans Am Fish Soc 93:215-226

Seber GAF (1982) The estimation of animal abundance. Charles Griffin \& Company, London

Shaffer ML (1981) Minimum population sizes for species conservation. Bioscience 31:131-134

Thompson MH, Dumont CP, Gaymer CF (2008) ISO 14001: towards international quality environmental management standards for marine protected areas. Ocean Coast Manag 51:727-739

- Wade PR (1998) Calculating limits to the allowable humancaused mortality of cetaceans and pinnipeds. Mar Mamm Sci 14:1-37

Westhead MC, Fenton DG, Koropatnick TA, Macnab PA, Moors HB (2012) Filling the gaps one at a time: the Gully Marine Protected Area in eastern Canada. A response to Agardy, Notarbartolo di Sciara and Christie. Mar Policy 36:713-715

> Whitehead H (2009) SOCPROG programs: analyzing animal social structures. Behav Ecol Sociobiol 63:765-778

Whitehead H (2013) Trends in cetacean abundance in the Gully submarine canyon, 1988-2011, highlight a $21 \%$ per year increase in Sowerby's beaked whales (Mesoplodon bidens). Can J Zool 91:141-148

- Whitehead H, Hooker SK (2012) Uncertain status of the northern bottlenose whale (Hyperoodon ampullatus): population fragmentation, legacy of whaling, and current threats. Endang Species Res 19:47-61

> Whitehead H, Wimmer T (2005) Heterogeneity and the mark-recapture assessment of the Scotian Shelf population of northern bottlenose whales (Hyperoodon ampullatus). Can J Fish Aquat Sci 62:2573-2585

Whitehead H, Christal J, Dufault S (1997a) Past and distant whaling and the rapid decline of sperm whales off the Galápagos Islands. Conserv Biol 11:1387-1396

Whitehead H, Gowans S, Faucher A, McCarrey S (1997b) Population analysis of northern bottlenose whales in the Gully, Nova Scotia. Mar Mamm Sci 13:173-185

> Wimmer T, Whitehead H (2004) Movements and distribution of northern bottlenose whales, Hyperoodon ampullatus, on the Scotian Slope and in adjacent waters. Can J Zool 82:1782-1794

Wood LJ, Fish L, Laughren J, Pauly D (2008) Assessing progress towards global marine protection targets: shortfalls in information and action. Oryx 42:340-351 